\title{
Anna Ascenzi, Il Plutarco delle donne. Repertorio della pubblicistica educativa e scolastica e della letteratura amena destinata al mondo femminile nell'Italia dell'Ottocento
}

Macerata, Edizioni Università, 2009, 214 p.

\section{Michel Ostenc}

\section{OpenEdition}

Journals

\section{Édition électronique}

URL : http://journals.openedition.org/assr/22015

DOI : 10.4000/assr.22015

ISSN : $1777-5825$

\section{Éditeur}

Éditions de l'EHESS

\section{Édition imprimée}

Date de publication : 31 décembre 2010

Pagination : 9-242

ISBN : 9782713223013

ISSN : 0335-5985

\section{Référence électronique}

Michel Ostenc, «Anna Ascenzi, II Plutarco delle donne. Repertorio della pubblicistica educativa e scolastica e della letteratura amena destinata al mondo femminile nell'Italia dell'Ottocento ", Archives de sciences sociales des religions [En ligne], 152 | octobre-décembre 2010, document 152-4, mis en ligne le 17 mai 2011, consulté le 21 septembre 2020. URL : http://journals.openedition.org/assr/22015 ; DOI : https://doi.org/10.4000/assr.22015

Ce document a été généré automatiquement le 21 septembre 2020

(c) Archives de sciences sociales des religions 


\section{Anna Ascenzi, Il Plutarco delle donne. Repertorio della pubblicistica educativa e scolastica e della letteratura amena destinata al mondo femminile nell'Italia dell'Ottocento}

Macerata, Edizioni Università, 2009, 214 p.

Michel Ostenc

\section{RÉFÉRENCE}

Anna Ascenzi, Il Plutarco delle donne. Repertorio della pubblicistica educativa e scolastica e della letteratura amena destinata al mondo femminile nell'Italia dell'Ottocento, Macerata, Edizioni Università, 2009, 214 p.

L'hégémonie culturelle de la bourgeoisie imposa, au XIX siècle, une conception sociale qui attribuait à la femme une fonction éducative majeure au sein de la famille. Anna Ascenzi étudie les ouvrages qui devaient préparer les jeunes filles italiennes à cette nouvelle mission. Nombre d'entre eux portaient les traces de la misogynie diffuse de Fénelon et de Rousseau qu'ils propageaient sous une forme accessible à leurs lectrices : dialogues édifiants, correspondances intimes, conseils d'une mère à sa fille, éloge de l'amour conjugal, apologie des vertus des femmes célèbres. La culture laïque des élites libérales italiennes était sans doute inconciliable avec celle des catholiques; mais Anna Ascenzi entend démontrer que le mythe libéral de la "charité éducatrice» correspondait parfaitement à la conception de l'Église. 
2 La féminisation du catholicisme avait influencé la pastorale et les nouvelles congrégations religieuses veillaient à l'éducation des filles pour en faire l'âme de la famille. Les méthodes pédagogiques de ces nouveaux instituts différaient profondément de celles des monastères d'Ancien Régime et la « ratio studiorum » du pensionnat des Dames du Sacré-Cœur à la Trinité aux Monts proposait, en 1828, un enseignement complet. La rhétorique, l'arithmétique, les sciences naturelles, les langues étrangères, l'histoire et la géographie figuraient au programme; mais son originalité venait d'un enseignement de philosophie destiné à préserver les élèves de tout indifférentisme religieux. L'Église souhaitait s'adresser à des mères vertueuses et l'un des ouvrages les plus répandus dans les milieux catholiques de la péninsule pendant la Restauration était le Trattato dell'educazione dei fanciulli de l'évêque gallican César de La Luzerne. Les livres du théologien Jean Joseph Gaume, traduits en italien dans les années 1850, concernaient la préparation au sacrement de la communion et dénonçaient le paganisme dans l'éducation. Une intransigeance doctrinale analogue animait les ouvrages de l'abbé Blanchard et du père Guy Toussaint Caron, deux prêtres réfractaires émigrés en Angleterre pendant la Révolution française. À l'instar des évêques Tommaso Ronna et Vincenzo Maria Strambi, ces ecclésiastiques doutaient de l'utilité des études scientifiques et philosophiques pour les filles; mais l'opposition à la pensée des Lumières incitait le courant contre-révolutionnaire à utiliser les vertus féminines pour restaurer la hiérarchie traditionnelle dans la famille

Deux théologiens fidéistes, l'abbé Louis Bautain et le père théâtin Gioacchino Ventura, figuraient parmi les auteurs les plus appréciés. Le premier proclamait la capacité de la foi à édifier des vérités fondamentales sans le secours de la raison, thèse condamnée par Rome en 1838. L'Église enseignait que la raison pouvait atteindre la vérité dans l'ordre des principes naturels. Le De jure ecclesiastico (1826) avait fait de Ventura le chef de la philosophie catholique en Italie; mais son engagement politique dans les mouvements révolutionnaires de 1848 le contraignit à s'exiler à Paris. Les ouvrages de Bautain restaient pourtant largement diffusés en Italie. Ils concernaient les crises de l'adolescence, les problèmes du noviciat et ceux des jeunes filles rebelles à la volonté de leurs parents. Le père Ventura était plein de prévention envers la culture féminine ; mais il reconnaissait à la femme une supériorité morale et ses livres insistaient sur les devoirs des époux. Le théologien génois Giuseppe Frassinetti aidait les adolescents et les jeunes mariés à vivre leur foi et Gian Battista Fenoglio publiait les pensées du père Tommaso Pendolà sur la jeunesse chrétienne et la femme pieuse. L'idéal catholique d'une épouse exemplaire, responsable de l'éducation morale et religieuse de ses enfants, s'inspirait sans doute des Saintes Écritures ; mais on le trouvait aussi dans une littérature imbue de la nécessité d'une éducation féminine capable d'éveiller les consciences

4 Le livre de monseigneur Dupanloup sur la femme studieuse fut certainement l'un des plus significatifs de la période. Il présentait la femme comme une créature raisonnable qui devait cultiver ses facultés intellectuelles tout en restant une maîtresse de maison accomplie, responsable de la morale de la famille et de l'éducation des enfants. La femme studieuse n'était donc pas une femme savante. Il existait pourtant en cette fin de siècle quelques ecclésiastiques italiens favorables à une éducation féminine plus poussée. L'évêque de Crémone, Geremia Bonomelli, en faisait partie, en préconisant l'émancipation de la femme de son rôle purement domestique, et il se montrait moins hostile que Dupanloup à l'idée de son intervention dans la vie politique et sociale ; mais 
cette évolution se heurtait à l'incompatibilité de la mission familiale de la mère italienne avec les contraintes intellectuelles d'une instruction supérieure. Anna Ascenzi s'en prévaut pour affirmer qu'une telle émancipation nécessitait une nouvelle définition de l'identité féminine. 